\title{
Can diabetes management programs create sustained improvements in disease outcomes?
}

\author{
Russell L. Rothman, Tom A. Elasy
}

$\infty \quad$ See related article page $\mathrm{I} 457$

$\mathrm{L}$ arge, well-conducted studies have demonstrated that intensive glucose control and cardiovascular risk reduction can significantly reduce the complications of diabetes. ${ }^{1-5}$ Cardiovascular risk reduction is critical because over two-thirds of patients with diabetes die of cardiovascular causes. ${ }^{3}$ Unfortunately, translating this evidence into clinical practice can be difficult, and in many patients the disease continues to be suboptimally controlled. ${ }^{6,7}$ One strategy for improving care for patients with diabetes has been disease management programs. Rather than the traditional model of health care delivery, which often focuses on acute problems and visit-based care, disease management creates an "organized system tailored to the complex problems of chronic illness." ${ }^{8}$ Disease management programs are typically characterized by the use of multidisciplinary teams that provide integrated approaches to care, evidencebased care algorithms, and information systems that allow for frequent tracking of patient-oriented outcomes and the adjustment of treatments. ${ }^{8-10}$ Most diabetes management programs have focused on glycemic control and reduced glycated hemoglobin $\left(A_{\mathrm{rC}}\right)$ concentrations by a clinically meaningful $\mathrm{\%} \%-2 \% .{ }^{11,12} \mathrm{~A}$ few, more recent studies have demonstrated that disease management can improve cardiovascular risk factors in addition to glycemic control. ${ }^{13,14}$

In a study published in this issue, ${ }^{15}$ Ménard and colleagues (see page I457) demonstrate again that an intensive disease management program can improve glycemic control and cardiovascular risk factors in patients with poorly controlled diabetes. In a small randomized trial, they found that patients who received intensive disease management had significant improvement in hemoglobin $\mathrm{A}_{\mathrm{IC}}$ concentrations, diastolic blood pressure, and low-density lipoprotein cholesterol and triglyceride levels at I2-month follow-up compared with a control group that continued with usual care. Of concern, however, the authors found that 6 months after the intensive multitherapy stopped, many of the patients' clinical outcomes had worsened, and there were no longer statistically o significant differences in hemoglobin $\mathrm{A}_{\mathrm{rC}}$ concentrations,

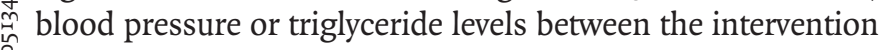
and control groups. Three explanations for these findings include lack of statistical power to adequately assess outcomes at I8-month follow-up; inadequate initial intervention to promote long-term improvement; and the natural history of patients to "relapse" (return to poor control) over time.
The study by Ménard and colleagues was small, with only 72 patients enrolled in the study and 6r ( 32 in the intervention group and 29 in the control group) completing the 18 -month evaluation. Sample estimates are not provided in the study, but the primary outcomes were targets recommended by the Canadian Diabetes Association (including hemoglobin $\mathrm{A}_{\mathrm{rc}}$ concentrations $<7 \%$, systolic blood pressure $<130 \mathrm{~mm} \mathrm{Hg}$, and low-density lipoprotein cholesterol levels $<2.5 \mathrm{mmol} / \mathrm{L}$ ). However, if one examines the results at 18 months as the amount of absolute improvement (see online Table 4, available at www.cmaj.ca/cgi/content/full/I73/I2/I457), one can see that there are some trends for improvement in the intervention group versus the control group. For example, intervention patients started with a hemoglobin $\mathrm{A}_{\mathrm{rc}}$ concentration of $9.1 \%$, which decreased to $7.5 \%$ at 12 months and then increased to $8.1 \%$ at 18 months for a net loss of $1.0 \%$, whereas control patients started with a hemoglobin $\mathrm{A}_{\mathrm{xc}}$ concentration of $9.3 \%$, which was at $8.6 \%$ at I 8 months. The $0.3 \%$ net difference between the 2 groups at 18 months is not large, but it

\section{The intervention failed to generate long-standing
behavioural change}

could be statistically significant in a larger study. The improvements in hemoglobin $\mathrm{A}_{\mathrm{IC}}$ concentrations in the control group can be related to secular improvements in care, regression to the mean or a Hawthorne effect (people change their behaviour because they know they're participating in a study), and are not an uncommon finding. The significant improvement in the control group, however, makes it even harder to demonstrate that the intervention was successful and emphasizes the importance of having a larger sample.

Ménard and colleagues were able to achieve impressive improvements in clinical outcomes and behavioural changes at I2 months. This is likely related to the intensive nature of their intervention, which included frequent management over the telephone. One plausible explanation for worsening out- 
comes at I8 months could be that the intervention failed to generate long-standing behavioural change in the participating patients. Current research focusing on motivational interviewing, improved education techniques, and other behavioural approaches may help promote behavioural changes that are sustained over time.

Finally, a major contribution to the worsening of clinical outcomes after the completion of an intervention may be related to the natural history of patients to "relapse" (return to poor control) over time. Results of the UK Prospective Diabetes Study suggest that patients have worsening glycemic control over time in part because of physiologic deterioration. ${ }^{16}$ It is unlikely, however, that the degree of deterioration seen in the current study would result from physiologic causes alone after just 6 months. A more plausible explanation is that the relapse occurs in the short term owing to behavioural reasons. Indeed, the data from Ménard and colleagues support the importance of self-care in preventing deterioration to worsening control. We have observed a $40 \%$ deterioration in glycemic control at I-year follow-up in patients who had previously attained adequate glycemic control. ${ }^{17}$ These patients may require a less intensive "maintenance" intervention to promote self-management over time.

The encouraging result from the study by Ménard and colleagues is that intensive disease management was able to significantly improve diabetes-related outcomes at 12 -month follow-up. Even if these results are not sustainable over time, the results of a recent study suggest that improved diabetes control may have long-term beneficial effects. In the Epidemiology of Diabetes Interventions and Complications follow-up study, ${ }^{18}$ patients who had received intensive glycemic therapy had lower rates of nephropathy than control patients 8 years after the study ended, even though the 2 groups had similar glycemic control at follow-up. These results suggest that patients who attain glycemic control may develop a "metabolic memory" that results in long-term benefits. Whether maintaining control for as short as one year will result in some residual benefit over time remains to be seen.

Continuing research into the role of disease management will help to discover improved initial interventions or additional, minimal "maintenance" interventions that can lead to sustained improvements in disease outcomes over time.

Russell Rothman and Tom Elasy are from the Division of General Internal Medicine, Department of Medicine, Center for Health Services Research, Vanderbilt University Medical Center, and the Vanderbilt Diabetes Center, Vanderbilt University Medical Center, Nashville, Tenn.
Competing interests: None declared for Tom Elasy. Russell Rothman currently receives research funding from NIDDK (K23 DKo65294), Pfizer Clear Health Communication Initiative and the American Diabetes Association.

\section{REFERENCES}

I. The Diabetes Control and Complications Trial Research Group. The effect of intensive treatment of diabetes on the development and progression of long-term complications in insulin-dependent diabetes mellitus. NEngl J Med I993;329:977-86.

2. UK Prospective Diabetes Study (UKPDS) Group. Intensive blood-glucose control with sulphonylureas or insulin compared with conventional treatment and risk of complications in patients with type 2 diabetes (UKPDS 33). Lancet I998;352:837-53.

3. Mooradian $\mathrm{AD}$. Cardiovascular disease in type 2 diabetes mellitus: current management guidelines. Arch Intern Med 2003;163:33-40.

4. Snow V, Weiss KB, Mottur-Pilson C. The evidence base for tight blood pressure control in the management of type 2 diabetes mellitus. Ann Intern Med 2003;138: 587-92.

5. Goldberg RB, Mellies MJ, Sacks FM, et al. Cardiovascular events and their reduction with pravastatin in diabetic and glucose-intolerant myocardial infarction survivors with average cholesterol levels: subgroup analyses in the cholesterol and recurrent events (CARE) trial. The Care Investigators. Circulation I998;98:2513-9.

6. Saaddine JB, Engelgau MM, Beckles GL, et al. A diabetes report card for the United States: quality of care in the I990s. Ann Intern Med 2002;136:565-74.

7. McGlynn EA, Asch SM, Adams J, et al. The quality of health care delivered to adults in the United States. NEngl J Med 2003;348:2635-45.

8. Bodenheimer T. Disease management - promises and pitfalls. $N$ Engl J Med I999;340:1202-5.

9. Bodenheimer T, Wagner EH, Grumbach K. Improving primary care for patients with chronic illness. JAMA 2002;288:1775-9.

Io. Bodenheimer T, Wagner EH, Grumbach K. Improving primary care for patients with chronic illness: the chronic care model, Part 2. JAMA 2002;288:I909-I4.

II. Renders CM, Valk GD, Griffin SJ, et al. Interventions to improve the management of diabetes in primary care, outpatient, and community settings: a systematic review. Diabetes Care 200I;24:I82I-33.

I2. Task Force on Community Preventive Services. Strategies for reducing morbidity and mortality from diabetes through health-care system interventions and diabetes self-management education in community settings. A report on recommendations of the Task Force on Community Preventive Services. MMWR Morb Mortal Wkly Rep 200I;50:I-I5.

13. Gaede P, Vedel P, Larsen N, et al. Multifactorial intervention and cardiovascular disease in patients with type 2 diabetes. N Engl J Med 2003;348:383-93.

I4. Rothman RL, Malone R, Bryant B, et al. A randomized trial of a primary care-based disease management program to improve cardiovascular risk factors and glycated hemoglobin levels in patients with diabetes. Am J Med 2005;II8:276-84.

I5. Ménard J, Payette H, Baillargeon JP, et al. Efficacy of intensive multitherapy for patients with type 2 diabetes mellitus: a randomized controlled trial. CMAJ 2005;I73(I2):I457-63.

I6. UK prospective diabetes study I6. Overview of 6 years' therapy of type II diabetes: a progressive disease. UK Prospective Diabetes Study Group. Diabetes 1995;44: I249-58.

17. Elasy TA, Graber AL, Wolff K, et al. Glycemic relapse after an intensive outpatient intervention for type 2 diabetes. Diabetes Care 2003;26:I645-6.

I8. Sustained effect of intensive treatment of type I diabetes mellitus on development and progression of diabetic nephropathy: the Epidemiology of Diabetes Interventions and Complications (EDIC) study. JAMA 2003;290:2159-67.

Correspondence to: Dr. Russell Rothman, Assistant Professor, Internal Medicine \& Pediatrics, Center for Health Services Research, Vanderbilt University Medical Center, Suite 60oo, Medical Center East, Nashville TN 37232-8300, fax 6I5 936-I269; russell.rothman@vanderbilt.edu

\section{IMPACT}

$C M A J$ is the $5^{\text {th }}$ leading international general medical journal as ranked by Thomson ISI. 2004 impact factor, 5.9. 